\title{
Investigation on Utilization of Phosphogypsum as a Partial Replacement of Cement in Concrete
}

\author{
Yasser R. Zaghloul \\ Assistant Professor \\ Higher Institute of Engineering, El-Shorouk City, \\ Cairo, Egypt
}

\begin{abstract}
The role of provide technology to promote the efficient use of minerals and ores and their processes waste is the main purpose of this research. Phosphogypsum is a phosphate fertilizer plants by-product and from some chemical industries, it can be used as a partial replacement of cement in concrete. This investigation has been carried out, in order to study the effect of partial replacement of cement with treated phosphogypsum (PG) in concrete. Phosphogypsum has been used with $3 \%, 7 \%$ and $10 \%$ percentages as partially replacement of cement. Results indicated that $10 \%$ of PG has improved the setting time, compressive strength, tensile strength and permeability of concrete. Further, it does not contribute to unsound paste. Also, it has improved the leachability of concrete which leads to be suitable in immobilization of radioactive waste. Eventually, from this investigation it can be recommended that, phosphogypsum has enormous prospect to be used in different concrete implementations.
\end{abstract}

Keywords- Phosphogypsum; Setting time; Soundness; Compressive strength; Splitting tensile strength; Industrial wastes reuses; Finite element model

\section{Introduction}

It is well known that, concrete is generally a mixture of cement, water and aggregates. Expansion in the infrastructure sector has led to an increase in cement demand, which has led to a gradual increase in cement cost. To overcome this dilemma and reduce the concrete costs; the use of wastes either solid or agricultural, and industrial by-products as partial replacement of cement in concrete became one of the most important needs nowadays.

For the role of provide technology to promote the efficient use of minerals and ores and their processes wastes, this research has conducted to identify and develop the use of Egyptian phosphogypsum which produces annually in huge amounts. Phosphogypsum (PG) is a type of gypsum that is obtained as a by-product of phosphate ores in the wet process of phosphoric acid production. It consists mainly of $\mathrm{CaSO}_{4} \cdot 2 \mathrm{H}_{2} \mathrm{O}$ and contains some impurities of environmental concern such as $\mathrm{P}_{2} \mathrm{O}_{5}, \mathrm{~F}^{-}, \mathrm{Si}$, organic substances and traces of some radioactive elements originate from the phosphate ores. The amount of PG produced during phosphoric acid production exceeds the mass of the product; about 5 tons of phosphogypsum are generated per 1 ton of phosphoric acid [1].

Just $15 \%$ of world creation of PG is reused as building material, agricultural composts or soil stabilization adjustment and as set controller in the Portland cement production [2]. The staying $85 \%$ is discarded with no treatment and these byproducts are usually disposed of in large weather-exposed warehouses that occupy a large area and cause genuine environmental damage. Also, passive atmospheric impacts can be occurred by vapors containing hazardous materials which emitted from this waste. Hence, the appropriate utilization of phosphogypsum after treated is necessity to take care of environmental and disposal problems. In different countries attempts have been made to find means of utilizing phosphogypsum.

Phosphate ore is an important economic deposit in Egypt and it is localized in three main regions. The total reserves are estimated to be more than 3 billion tons [3]. Abu Tartur phosphate deposit is one of the largest phosphate mining areas in the Middle East. This ore is widely used in Egyptian factories to produce phosphoric acid, which accompanied with the production of huge amount of PG. On the other hand, one of the essential uses of cement in nuclear industry is its use in immobilization of radioactive wastes, to prevent their dispersion to the environment, which needs a good leachability of the concrete mixture.

Singh (2002) [4], has been reported that pure PG can be utilized as a partial substitute in cement since $\mathrm{P}_{2} \mathrm{O}_{5}, \mathrm{~F}^{-}$and radioactivity in $\mathrm{PG}$ diminishes after treatment by aqueous citric acid. Altun and Sert (2004) [5] concluded that pure PG can be utilized as a retarder instead Portland cement. The best compressive strength after 28 days was appeared in specimens with 3\% PG. Bhadauria and Thakare (2006) [6] concluded that the mix in which the cement was replaced with $5 \%$ phosphogypsum had almost the same standard or normal consistency as ordinary cement and therefore water requirement for the phosphogypsum cement mixture is narrowly affected. They also reported that phosphogypsum in ordinary Portland cement mixtures significant delays the setting time and improved the compressive strength of concrete. Finally, Kumar (2003) [7] reported that the fly ash limestone phosphogypsum hollow block is perhaps the best substitute for traditional burnt mud hollow bricks or hollow concrete blocks in the construction industry.

The present work transacts to experimental investigations of some physical and mechanical characteristics of concrete using PG of different ratios as partial replacement of cement with water-cement ratio of 0.45 . In addition, investigates the ability of this type of concrete to be used in immobilization of 
radioactive waste by studying the leachability of all investigated specimens.

\section{Materials}

All materials used are locally produced. Investigation materials used were Cement, Fine aggregate, Coarse aggregate and Phosphogypsum.

\section{A. Cement}

Ordinary Portland cement (CEM I-42.5) was used. The cement has specific gravity of 3.15 and fineness of $2.9 \times 10^{5}$ $\mathrm{mm}^{2} / \mathrm{g}$.

\section{B. Fine Aggregates}

Natural sand with specific gravity of 2.61 was used as fine aggregates in the concrete specimens. The grading analysis of sand is presented in Table (1).

\section{Coarse Aggregates}

Dolomite is a fam ous coarse aggregate which is used in usual ordinary concretes instead of the natural gravel. Dolomite is widely used as coarse aggregates because it possesses; the ability to produce required sizes, ease of handling and satisfactory results obtained. Dolomite with specific gravity of 2.55 was used and its sieve analysis is presented in Table (2). The grading of coarse aggregate was in compliance with ACI 211.1-91 [8].

\section{Phosphogypsum}

Phosphogypsum (PG) was obtained from Abu-Zabal Company for Fertilizers and Chemicals. Table (3) reported the chemical analysis of different Egyptian phosphogypsum samples by other researchers in comparison with chemical analysis of the investigated sample [9-12]. It is clear that, no fundamental differences in chemical analysis is observed. However, the slight differences are related to the origin of the phosphate ore and the plant operation efficiency. Before use, it has to be treated as given by El-Afifi et al., [9].

\section{Experimental work}

\section{A. Mix Proportions}

Concrete mixtures using different mix proportions of PG were initially performed. Six concrete mixtures were enhanced and utilized in the present study. The proportions of the mixtures are presented in Table (4). The specimens of standard cubes $(150 \mathrm{~mm} \times 150 \mathrm{~mm} \times 150 \mathrm{~mm})$, and standard cylinders of (150 $\mathrm{mm}$ diameter $\times 300 \mathrm{~mm}$ height) were cast with various percentage replacements of PG. Also, for leaching test, pellets of dimensions $2 \mathrm{~cm}$ diameter and $1 \mathrm{~cm}$ height were prepared. The added water, for pellets different mixtures, contains a tracer (uranyl nitrate) of concentration $20 \mathrm{mg} / \mathrm{ml}$. The amount of uranium leaked from the pellets to the leachant is measured spectrophotometrically after a period of $72 \mathrm{hr}$, [13].

Table (1): Grading of Sand

\begin{tabular}{|c|c|c|c|c|c|c|}
\hline $\begin{array}{c}\text { Sieve size } \\
(\mathbf{m m})\end{array}$ & 4.76 & 2.40 & 1.20 & 0.60 & 0.30 & 0.15 \\
\hline $\begin{array}{c}\text { Sand } \\
\text { (Passing \%) }\end{array}$ & $95-100$ & $90-95$ & $70-80$ & $15-25$ & $10-20$ & 0 \\
\hline
\end{tabular}

Table (2): Grading of Different Coarse Aggregates

\begin{tabular}{|c|c|c|c|c|c|}
\hline $\begin{array}{c}\text { Sieve size } \\
(\mathbf{m m})\end{array}$ & 38 & 19 & 9.5 & 4.75 & 2.36 \\
\hline $\begin{array}{c}\text { Dolomite } \\
\text { (Passing \%) }\end{array}$ & 100 & $95-100$ & $20-30$ & $0-5$ & 0 \\
\hline $\begin{array}{c}\text { ACI Limit } \\
\text { (Passing \%) }\end{array}$ & 100 & $90-100$ & $20-55$ & $0-10$ & $0-5$ \\
\hline
\end{tabular}

Table (3): Different chemical analyses of PG (wt \%)

\begin{tabular}{|c|c|c|c|c|c|}
\hline Elements* & $\begin{array}{c}\text { El-Afifi } \\
\text { et. al., [9] }\end{array}$ & $\begin{array}{c}\text { Taher, } \\
{[\mathbf{1 0}]}\end{array}$ & $\begin{array}{c}\text { Ibrahim, } \\
{[\mathbf{1 1}]}\end{array}$ & $\begin{array}{c}\text { Didamony, } \\
\text { et. al. [12] }\end{array}$ & $\begin{array}{c}\text { Investigated } \\
\text { sample }\end{array}$ \\
\hline $\mathbf{C a O}$ & 38.40 & 32.13 & 28.40 & 30.20 & 35.90 \\
\hline $\mathbf{S O}_{\mathbf{3}}$ & 53.20 & 37.60 & 39.10 & 41.10 & 44.08 \\
\hline $\mathbf{S i O}_{\mathbf{2}}$ & 5.53 & 8.78 & 5.18 & 2.27 & 6.95 \\
\hline $\mathbf{P}_{\mathbf{2}} \mathbf{O}_{\mathbf{5}}$ & 2.05 & 1.82 & 2.40 & 1.56 & 2.38 \\
\hline $\mathbf{F e}_{\mathbf{2}} \mathbf{O}_{\mathbf{3}}$ & -- & 0.35 & 3.85 & 1.74 & 1.64 \\
\hline $\mathbf{N a}_{\mathbf{2}} \mathbf{O}$ & 0.49 & -- & 0.14 & 0.14 & 0.24 \\
\hline $\mathbf{F}$ & 1.14 & 0.80 & 1.39 & 1.39 & 0.76 \\
\hline
\end{tabular}

* There are some other trace elements present in the samples

Table (4): Mix Proportions of the Concrete Mixtures.

\begin{tabular}{|c|c|c|c|c|c|}
\hline No. & PG wt. \% & $\begin{array}{c}\text { Cement } \\
\mathbf{K g} / \mathbf{m}^{\mathbf{3}}\end{array}$ & w/c ratio & $\begin{array}{c}\text { Fine } \\
\text { Agg. } \\
\mathbf{K g} / \mathbf{m}^{3}\end{array}$ & $\begin{array}{c}\text { Coarse } \\
\text { Agg. } \\
\mathbf{K g} / \mathbf{m}^{3}\end{array}$ \\
\hline S1 & 0 & 400 & 0.45 & 700 & 1110 \\
\hline S2 & 3 & 388 & 0.45 & 700 & 1110 \\
\hline S3 & 7 & 372 & 0.45 & 700 & 1110 \\
\hline S4 & 10 & 360 & 0.45 & 700 & 1110 \\
\hline S5 & 12 & 352 & 0.45 & 700 & 1110 \\
\hline S6 & 15 & 340 & 0.45 & 700 & 1110 \\
\hline
\end{tabular}

\section{B. Methods of Testing}

All experiments were carried out on three samples and the average of the obtained results was considered. The setting times were measured for all specimens using a Vicat needle. Also, the soundness of cement was conducted according to ASTM C 88-13 [14] because the raw phosphogypsum is known to have some impurities therefore it is imperative to quantify soundness of paste made with cement replacement. On the other hand, mechanical properties of studied concrete specimens were determined. A 200-ton hydraulic compression testing machine has been used for determining the compressive strength for cubic specimens. However, cylindrical specimens have been used for determining splitting tensile strength according to ASTM C 496M-04 [15]. Also, after 28 days of preparation for the water permeability test, cylindrical specimens of various types of concrete were also used. The specimen surface is smoothed and cleaned, and the lateral portion of the specimen cylinder is coated with epoxy with non-shrinkage property to prohibit water leakage. The top of the sample was exposed to 1 bar water pressure for 48 hours, followed by 24 hours 3 bars and finally 24 hours 7 bars. The sample is then split using lateral compression loads. Depth of water penetration is measured in several places and averages are recorded. Furthermore, the apparatus used for 
leaching test is named Soxhlet-leachability apparatus as shown in Fig.(1). The pellet specimen is suspended in a cup which in turn is suspended in the Soxhlet as shown in Fig.(1). The Soxhlet is tightly connected to a round bottom flask containing $300 \mathrm{ml}$ deionized water as the leachant. The leachant is boiled and the vapor produced passed through the condenser. The condensed vapors are allowed to pass through the pellet then collected in the flask. The process is recycled continuously for a period of $72 \mathrm{hr}$, [16].

\section{Results and Discussions}

The workability of fresh concrete was determined by conducting test according to ASTM C 143M-03 [17]. The slump of fresh concrete without phosphogypsum (S1) was found to be $59 \mathrm{~mm}$ and with $10 \%$ phosphogypsum (S4) was $49 \mathrm{~mm}$. With further replacement of cement with phosphogypsum (S5 and S6) it is very difficult to mix the concrete due to inappropriate water - cement ratio, which make the concrete comparatively viscous. Therefore, all investigations will be carried for S1, S2, S3 and S4.

\section{A. Setting Times (initial and final)}

It was found that even with the replacement of three percent phosphogypsum the initial and final time was more than that of control specimen. The results for both initial and final setting time are displayed in table (6).

\section{B. Soundness Test}

The soundness of cement paste was specified. It is essential to determine soundness of any paste made with substituting cement. The test outcomes are introduced in table (7). The results declared that even $10 \%$ substitution of cement by PG does not provided to unsound paste.

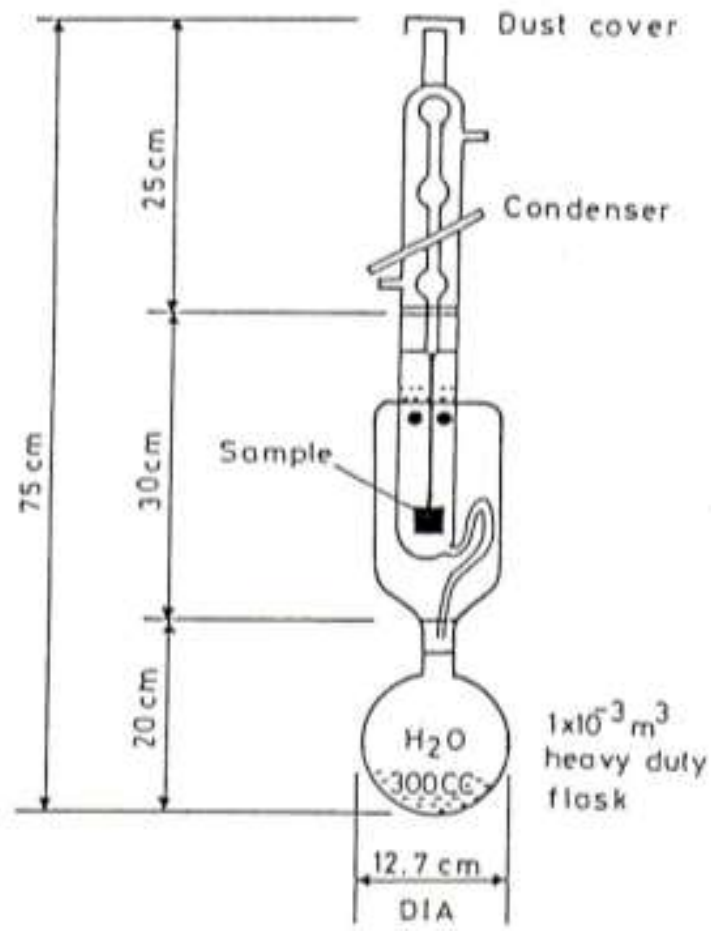

Fig. (1): Soxhlet Leachability Apparatus [16]
Table (6): Setting time of studied specimens

\begin{tabular}{|c|c|c|}
\hline No. & Initial Setting time (min.) & Final setting time (min.) \\
\hline S1 & 120 & 170 \\
\hline S2 & 130 & 190 \\
\hline S3 & 150 & 210 \\
\hline S4 & 180 & 240 \\
\hline
\end{tabular}

Table (7): Soundness of studied specimens

\begin{tabular}{|c|c|}
\hline No. & Soundness $(\mathbf{m m})$ \\
\hline S1 & 0.85 \\
\hline S2 & 1.55 \\
\hline S3 & 2 \\
\hline S4 & 3 \\
\hline
\end{tabular}

\section{Compressive Strength}

The specimens were cast with concrete mixes mentioned and cured for 7 and 28 days in the laboratory. On completion of the curing period the specimens were taken out and tested to assess performance of concrete. Fig.(2) represent the effect of curing age on the compressive strength of phosphogypsum concrete cubes. Each value represents average value of three tested specimens.

The Figure shows that, there is an increase in compressive strength of concrete with $10 \%$ replacement. Such increase in compressive strength may be due to the pozzolanic nature of PG and its filling ability which improve the compact ability.

\section{Tensile Strength}

The splitting tensile strength results for all mixes were studied and the obtained results are shown in Fig.(3). The results indicate that the tensile strength has the same trend like the compressive strength. It increases with PG percentage up to $10 \%$ replacement.

\section{E. Permeability Test}

Fig.(4) shows the results of the depth of water penetration which refers to the permeability of the investigated specimens. From this figure it can be seen that in the S4 sample, where $10 \%$ of cement was replaced with PG, the lowest water depth is observed. The depth of penetration decreased from $29 \mathrm{~mm}$ for $\mathrm{S} 1$ samples to $13 \mathrm{~mm}$ for $\mathrm{S} 4$ samples. This shows that about $55 \%$ decrease of water penetration can be obtained by the addition of $10 \%$ PG which fill small spaces in the concrete. Thus, concrete that is denser than ordinary concrete is acquired. This result has a positive effect on improving the leaching properties of the test sample, which is very important for nuclear waste disposal.

\section{F. Leachability Test}

Leachability test was applied for the prepared pellets. The leaching rates $(\mathrm{R})$ for the different specimens have been evaluated using the following equation given by Hespe (1971) [16];

$$
R=\frac{\mathrm{C} W}{\operatorname{CoAt}}
$$

where, $\mathrm{R}=$ Soxhlet leach rate $\left(\mathrm{gm} / \mathrm{cm}^{2} . \mathrm{d}\right)$

$\mathrm{C}=$ concentration of the released uranium in solution 
$\mathrm{Co}=$ initial concentration of uranium in the specimen

$\mathrm{W}=$ initial specimen weight $(\mathrm{gm})$

$\mathrm{A}=$ geometric surface area of specimen $\left(\mathrm{cm}^{2}\right)$

$\mathrm{t}=$ time of leaching in days

The values of $\mathrm{R}$ for the different specimens were calculated, the data obtained are given in table (8) for the different leachant solutions after 72 hours.

It is clear from this table that, the replaced of $10 \%$ of cement by PG leads to a decrease in leaching rate compared to that of cement alone. It is clear that the sequence of the leaching rate for uranium is agreement with the sequence of the permeability.

\section{Conclusion}

Based on the limited experimental investigation conducted and the analysis of test results, the following conclusions are drawn.

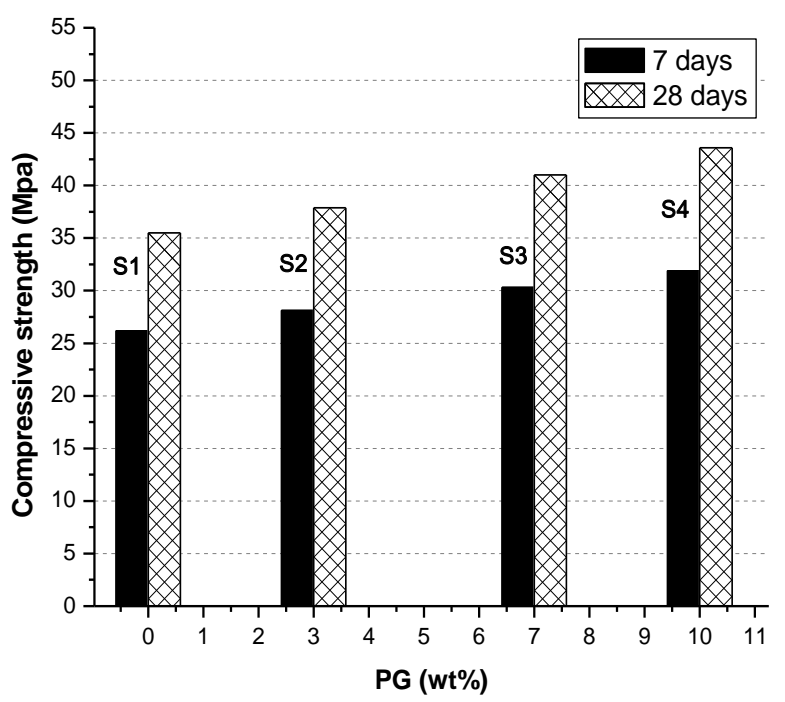

Fig. (2): Compressive strength of all concrete mixtures

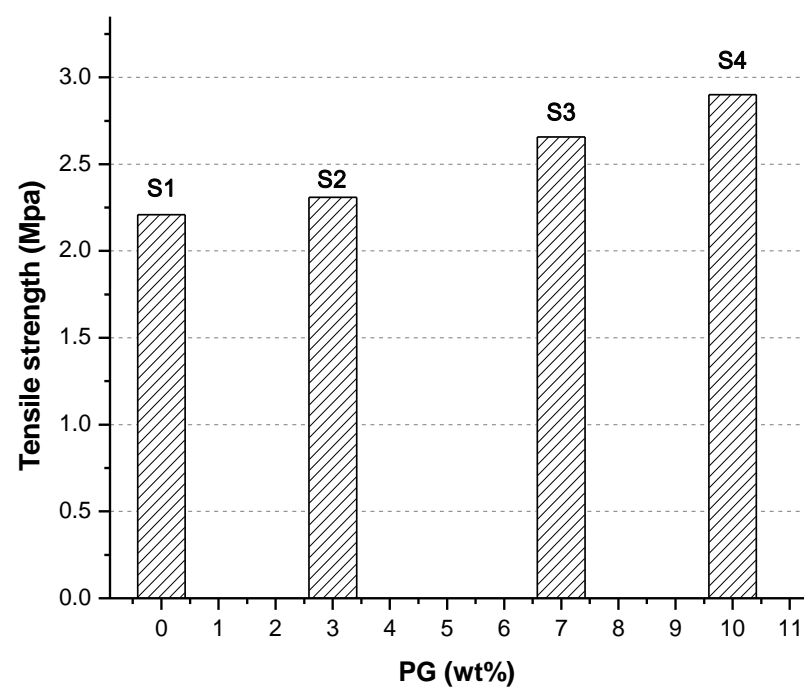

Fig. (3): Splitting tensile strength of all concrete mixtures

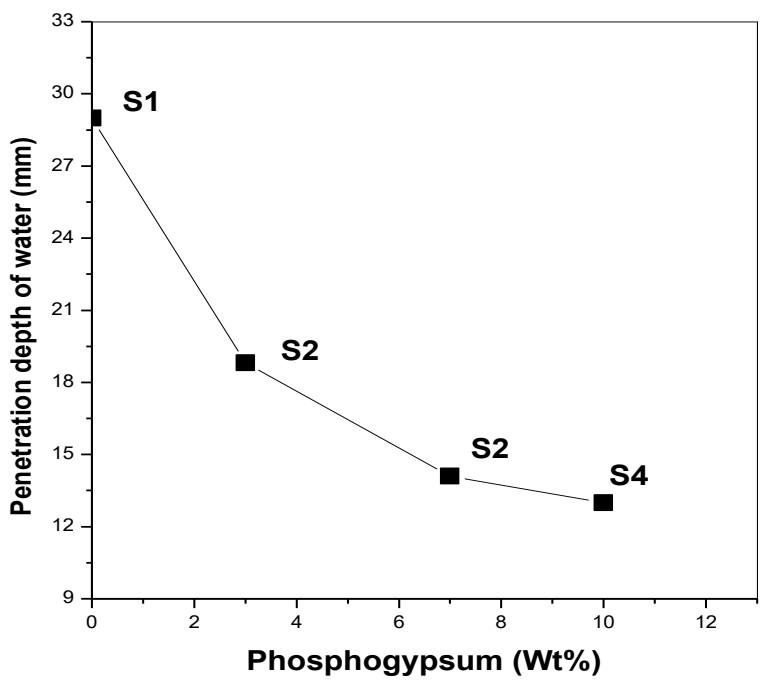

Fig. (4): Water penetration depth of all concrete mixtures

Table (8): The leaching rate of uranium for the different specimens

\begin{tabular}{|c|c|}
\hline No. & $\begin{array}{c}\text { Leaching Rate } \\
\left(\mathbf{g m} / \mathbf{c m}^{\mathbf{2}} \mathbf{. d}\right)\end{array}$ \\
\hline S1 & $6.8 \times 10^{-3}$ \\
\hline S2 & $6.2 \times 10^{-3}$ \\
\hline S3 & $5.8 \times 10^{-3}$ \\
\hline S4 & $5.5 \times 10^{-3}$ \\
\hline
\end{tabular}

- Industrial wastes such as phosphogypsum contribute to the development of concrete strength and can therefore be used in the construction industry for the production of concrete with partial cement replacement, which is a valuable component for economical concrete.

- Phosphogypsum in ordinary Portland cement mixtures often slows down the setting time, but is not involved in the production of unsound cement paste.

- With $10 \%$ substitution of cement by phosphogypsum, not only the compressive strength increased obviously with age but also the split-tensile strength after 28 days. However, further replacement of cement with phosphogypsum with the same water/cement ratio leads to viscous paste which is not suitable to be tested.

- Phosphogypsum improve the permeability of the concrete which leads to improvement in the leachability. Subsequently, concrete with phosphogypsum is appropriate for immobilization of radioactive waste.

From this investigation it can be recommended that, phosphogypsum has tremendous possibility to be utilized in different concrete applications because it contributes in strength improvement and in reducing the cost of the construction works. In addition, an essential use is to immobilize the radionuclides to prevent their dispersion to the environment and hence their hazardous effects. 


\section{Reference}

[1] Yang L., Yan Y., and Hu Z., "Utilization of phosphogypsum for the preparation of non-autoclaved aerated concrete", Construction and Building Materials, 44, 600-606, (2013). doi:10.1016/j.conbuildmat.2013.03.070

[2] Degirmenci N., Okucu A. and Turabi A. "Application of phosphogypsum in soil stabilization”, Building. Environ. 42, 33933398, (2007) doi:10.1016/j.buildenv.2006.08.010

[3] Aly H.F., Ali M.M. and Taha M.H. "Dissolution kinetics of western deseret phosphate rocks, Abu Tartur with hydrochloric acid", Arab Journal of Nuclear Science and Applications, 46, 1-16, (2013).

[4] Singh M., "Treating waste phosphogypsum for cement and plaster manufacture", Cement Concrete Research, 32, 1033-1038, (2002). doi: 10.1016/S0008-8846(02)00723-8

[5] Altun I.A. and Sert Y., "Utilization of weathered phosphogypsum as set retarder in Portland cement", Cement Concrete Research, 34, $677-680,(2004)$ doi:10.1016/j.cemconres.2003.10.017

[6] Bhadauria S.S.and Thakare R.B., "Utilization of phosphogypsum in cement mortar and concrete", $31^{\text {st }}$ Conference on our world in concrete \& structures: 16 - 17 August 2006, Singapore, (2006), http://cipremier.com/100031016.

[7] Kumar S., "Fly ash-lime-phosphogypsum hollow blocks for walls and partitions", Building and Environment, 38, 291-295, (2003). doi:10.1016/S0360-1323(02)00068-9

[8] ACI 211.1- 91, Standard practice for selecting proportions for normal, heavy weight, and mass concrete, (2002).

[9] El-Afifi E.M., Hilal M.A., Attallah M.F., El-Reefy S.A., "Characterization of phosphogypsum wastes associated with phosphoric acid and fertilizers production", Journal of Environmental Radioactivity, 100, 407-412, (2009). http://dx.doi.org/10.1016/j.jenvrad.2009.01.005

[10] Taher M.A., "Influence of thermally treated phosphogypsum on the properties of Portland slag cement", Resources, Conservation and Recycling, 52, 28-38, (2007). http://dx.doi.org/10.1016/j.resconrec.2007.01.008

[11] Ibrahim M.A., "Radiological studies and treatment of phosphogypsum wastes produced from phosphate ore processing", PhD. Faculty of Science, Zagazig University, (2011).

[12] El-Didamony H., Gado H.S., Awwad N.S., Fawzy M.M. and Attallah M.F., "Treatment of phosphogypsum waste produced from phosphate ore processing", Journal of Hazardous Materials, 245, 596-602, (2013). http://dx.doi.org/10.1016/j.jhazmat.2012.10.053

[13] Marcezenko Z., "Spectrophotometric determination of elements", John Wiley and Sons Inc., N.Y., (1986).

[14] ASTM C 88-13, Standard Test Method for Soundness of Aggregates by Use of Sodium Sulfate or Magnesium Sulfate, (2013).

[15] ASTM C 496M-04, Standard test method for splitting tensile strength of cylindrical concrete specimens, (2004).

[16] Hespe E.D., "Leach test of immobilized radioactive waste solids: A proposal for standard methods", Atomic Energy Rev., No. 9, p.195, (1971).

[17] ASTM C 143M-03, Standard Test Method for Slump of HydraulicCement Concrete, (2003). 